\title{
The effect of diazepam on human gastric secretion
}

\author{
D. BIRNBAUM, F. KARMELI, AND MAKONNEN TEFERA \\ From the Gastroenterological Service, Hadassah Hebrew University Hospital, Jerusalem, Israel
}

SUMMARY Human basal gastric secretion is markedly reduced after oral administration of $10 \mathrm{mg}$ diazepam. This effect lasts for five hours.

Gastric nocturnal secretion, collected five hours after the last meal, reveals a decline towards the morning hours with an average of $25 \%$ in placebo-treated patients. A comparison between placebo and diazepam reveals a significantly greater decrease of $47 \%$ in volume after giving parenterally $10 \mathrm{mg}$ diazepam without noticeable side effects.

The functional symptoms arising in the gastrointestinal tract may be caused by disturbance of visceral muscular activity, and of secretion and by alterations in blood flow.

Duodenal ulcer may be due to hyperactivity of gastric motor and secretory function, and one of the premises of the psychosomatic theory is that emotional conflict, mainly anxiety and psychic trauma, may induce such hyperactivity (Beaumont, 1833; Wolf, 1965). With these aspects in mind and the results of previous observations in rats (Birnbaum, 1968), a study on the effect of diazepam on human gastric secretion was initiated.

\section{Methods}

In the first series basal gastric secretion in 20 duodenal ulcer patients was studied without and with premedication with diazepam. The patients were tested after a 12-hour fast. Gastric aspiration aiming at complete evacuation preceded the collection period. For one hour aspiration was continued at intervals of two to three minutes and samples were collected every 10 minutes. Diazepam, in a dose of $10 \mathrm{mg}$, was given by mouth and the collection of gastric secretion was interrupted for 30 minutes. After complete aspiration of the fluid content of the stomach samples were again collected according to the method described above during one hour.

The duration of the pharmacological effect was studied in 19 patients from whom gastric juice had been collected according to the method described.

In a third group, 24 patients, mostly suffering from duodenal ulcer, were studied during the six night hours (11pm-5am) after intubation of the stomach Received for publication 11 May 1971. five hours after the last meal. Gastric content was aspirated and did not contain any food residue. Twelve of these patients received, after a control collection of gastric secretion for one hour, an intramuscular injection of $10 \mathrm{mg}$ diazepam while the control group received at the same time the solvent of diazepam alone.

In another series of $\mathbf{2 0}$ duodenal ulcer patients the effect of diazepam on the duration of achlorhydria after $840 \mathrm{mg}$ calcium carbonate was studied. These patients were intubated after a 12-hour fast and the concentration of acid was determined. Calcium carbonate was given by mouth and samples of $1 \mathrm{ml}$ gastric juice were aspirated every five minutes and titrated against $0.05 \mathrm{~N}$ sodium hydroxide with Töpfer reagent and phenolphthalein as indicators. The disappearance of free acid measures the duration of achlorhydria. Ten $\mathrm{mg}$ of diazepam was given by mouth and after $\mathbf{3 0}$ minutes the gastric content was aspirated. Acidity was determined and calcium carbonate administered. Achlorhydria was determined according to the method described above.

\section{Results}

In our first series of experiments a significant decrease of $32.0 \mathrm{ml} / \mathrm{hr} \pm 8.61(\mathrm{SE})$ in volume $(\mathrm{P}<0.01)$ and $1.64 \mathrm{mequiv} / \mathrm{hr} \pm 0.527(\mathrm{SE})$ in acid output $(P<0.01)$ was observed 30 to 90 minutes after an oral dose of $10 \mathrm{mg}$ diazepam compared with the preceding period of collection of basal gastric secretion during one hour.

The inhibitory effect of diazepam was observed during five hours. Results are summarized in Figure 1. The statistical evaluation of paired data of each hourly collection shows highly significant differences 


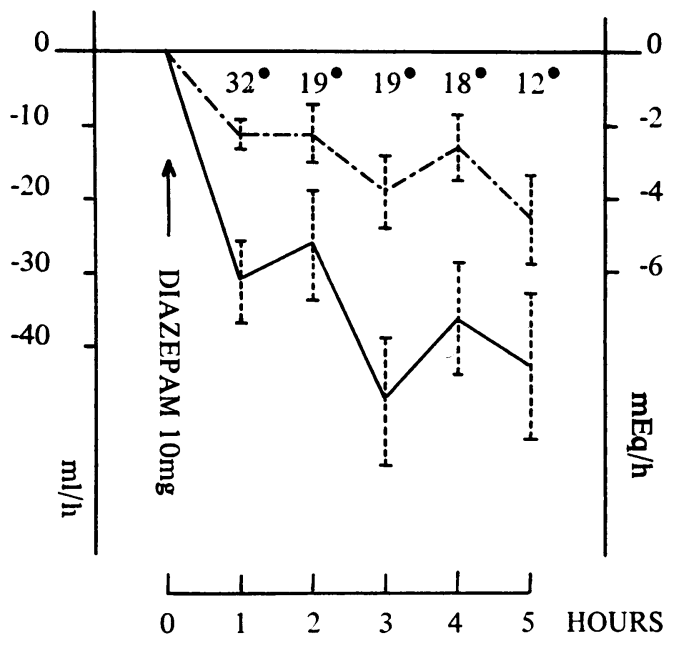

Fig. 1 Variations of mean hourly volume and acid output following diazepam. _-Volume; - - - - total acid output; $O$ basal secretion; $;$ average $\pm S E$;

number of patients.

$$
\text { i }
$$

( $t$ values in the range of 2.70 to 5.57 and $P$ values $<0.01)$ for the volume rate and total acid output.

In collections of basal gastric secretion during two to three hours no statistical difference in hourly volume and acid output was observed.

The results obtained in observations on the effect of diazepam or placebo on human night secretion are summarized in Figure 2. The decrease in volume of gastric secretion after parenteral administration of $10 \mathrm{mg}$ diazepam is statistically significant in comparison with that after a placebo (Student's $t$ test; $t$ values from 2.09 to $3 \cdot 23$, all $P$ values $<0.05$ ).
Similar variations are observed in total acid output which on the average during five hours shows a decrease in acid output of $52.4 \%$ after diazepam, while after placebo an average decrease in acid output of $37.8 \%$ was observed. The statistical evaluation of the hourly differences reveals only at the third hour of collection a t value of $2.57(\mathrm{P}<0.02)$ Although there exists a difference in total acid output between diazepam and placebo during five hours, this difference is not significant, the fact of which can be explained by the wide variations as well as the relatively small number of patients studied.

The fourth series of observations concerns the effect of diazepam on the duration of achlorhydria following the intake of calcium carbonate. The results of 20 tests compared with those obtained following calcium carbonate without premedication reveal a prolongation of achlorhydria from 22 to 37 minutes $(t=3.09, P<0.01)$.

\section{Comment}

Diazepam, a benzodiazepine derivative, decreases effectively unstimulated human basal gastric secretion and acid output. A dose of $10 \mathrm{mg}$ produces a significant inhibitory response which lasts up to five hours.

In previous studies (Birnbaum, 1969) we investigated some of the pharmacological effects of diazepam on the gastrointestinal tract. A significant inhibition of basal and stimulated human salivary secretion after oral administration of a dose of $10 \mathrm{mg}$ diazepam was observed (Steiner, Birnbaum, Karmeli, and Cohen, 1970). In rat experiments, a highly significant delay in gastric emptying was noted after diazepam given before a standard meal, though some of the contrast material reached a distance in the

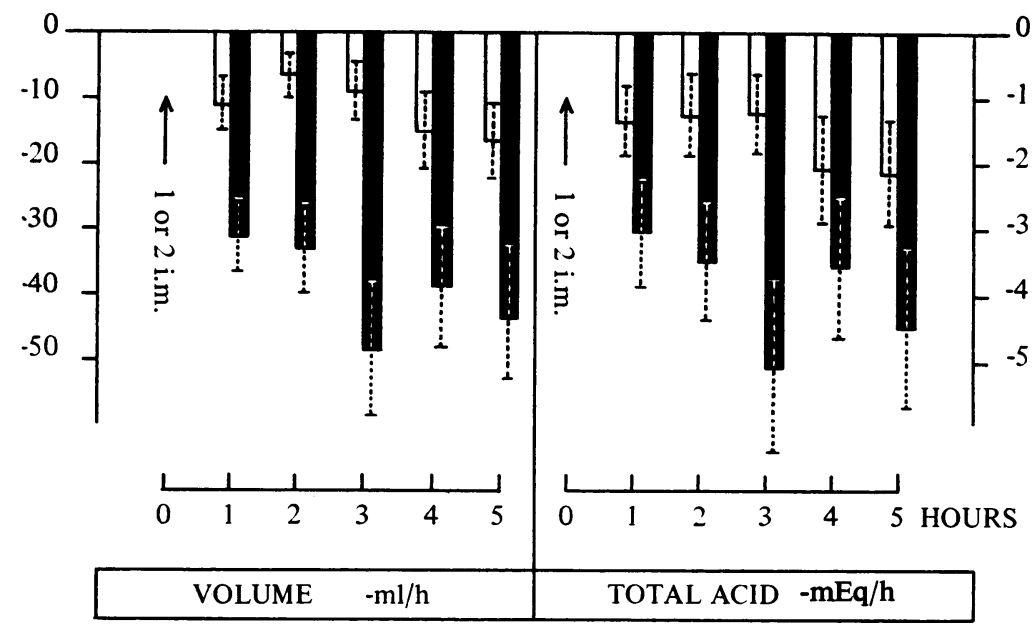

Fig. 2 Comparison of mean hourly volume and acid output following diazepam - 1 and placebo - 2. Diazepam - 1 -; $\square$ placebo - $2-;$ ? $\pm$ average $\pm S E ; 0$ basal secretion. 
ileum similar to that in untreated rats. In radiological studies in ulcer patients, serving as their own controls, a delaying effect of gastric and intestinal motility was observed in 10 out of 15 patients (Birnbaum, Ben-Menachem, and Schwartz, 1970).

In view of the delay in motility observed in the radiological study, the possibility of prolongation of achlorhydria induced by a promptly acting antacid was investigated. A statistically significant delay was observed, which, however, is only of minor clinical importance, the duration of achlorhydria being prolonged by 15 minutes only.

Nocturnal gastric secretion starting four to five hours following the last meal provides information on gastric secretory activity in patients who are asleep so that as well as the normal physiological stimuli for gastric secretion being inhibited those in the environment exciting and inhibiting gastric secretion were also excluded.

The investigation on the effect of diazepam on secretion at night was also prompted by the accepted opinion that duodenal ulcer patients secrete a two- to three-fold amount of highly acid gastric juice during the night.

In our group of patients we found variations in the rate of secretion indicating a decline in volume towards the morning hours, averaging in the placebotreated patients $25.6 \%$ while diazepam-treated patients revealed a significantly different decrease of $47 \%(\mathrm{t}=2.46, \mathrm{P}<0.05)$. The results obtained with diazepam on nocturnal gastric secretion in human subjects showed a significant decrease in outputs comparable with those obtained with some anticholinergic drugs at levels causing considerable side effects. Although the inhibition achieved with diazepam at a dose of $10 \mathrm{mg}$ is not equal to that observed following surgical vagotomy (Dragstedt, Palmer, Schafer, and Hodges, 1944), the lack of side effects which are observed with diazepam allows an increase in the dose which may result in a comparable 'medical vagotomy' during the night hours. The decrease in gastric secretion was achieved by a drug which has no anticholinergic effect in vitro and the mechanism of which has to be assumed in its action on higher regulatory structures of autonomic function in the central nervous system. Stimulation of these higher structures under the influence of stressful situations (Miller, Bergei, and Hawk, 1920; Mittelmann and Wolff, 1942; Todd, 1930) of unresolved hostility and anxiety is apparently modified by diazepam which has been shown to inhibit also the effects of stereotactic stimulation of certain areas in the hypothalamus (Morillo, 1967; Schallek, and Zabransky, 1966)

As a result of (unpublished) studies on patients with active duodenal ulcer, based on a clinical evaluation of the drug in 173 duodenal ulcer patients and a controlled double-blind study in 30 patients, diazepam may be considered a beneficial aid in ulcer therapy.

\section{References}

Beaumont, W. (1833). Experiments and Observations on the Gastric Juice and the Physiology of Digestion. Allen, Plattsburgh.

Birnbaum, D. (1968). The effect of valium on basal gastric secretion in rats. Med. Psychosom., 23, 1.

Birnbaum, D. (1969). The influence of psychotropic drugs on gastrointestinal function: experimental and clinical data. In Psychotropic Drugs in Internal Medicine: An International Symposium (int. Congr. Ser., 182). Excerpta med. (Amst.), pp. 101-108. Excerpta Medical Foundation, Amsterdam.

Birnbaum, D., Ben-Menachem, J., and Schwartz, A. (1970). The influence of oral diazepam on gastrointestinal motility. Amer. $J$. Proctol., 21, 263-267.

Dragstedt, L. R., Palmer, W. L., Schafer, P. W., and Hodges, P. C. (1944). Supradiaphragmatic section of the vagus nerves in the treatment of duodenal and gastric ulcers. Gastroenterology, 3, 450-471.

Miller, R. J., Bergeim, O., and Hawk, P. B. (1920). Gastric response to foods. IV. The influence of worry on gastric digestion. Science, $52,253$.

Mittelmann, B., and Wolf, H. G. (1942). Emotions and gastroduodenal function: Experimental studies on patients with gastritis, duodenitis and peptic ulcer. Psychosom. Med., 4, 5-61.

Morillo, A. (1967). Effects of benzodiazepines upon amygdala and hippocampus of the cat. Int. J. Neuropharmacol., 1, 353-359.

Schallek, W., and Zabransky, F. (1966). Effects of psychotropic drugs on pressor responses to central and peripheral stimulation in cat. Arch. int. Pharmacodyn., 166, 126-131.

Steiner, J. E., Birnbaum, D., Karmeli, F., and Cohen, S. (1970). Effect of diazepam on human salivary secretion. Digestion, 3, 262-268.

Todd, T. W. (1930). Behaviour Patterns of the Alimentary Tract. Williams and Wilkins, Baltimore.

Wolf, S. (1965). The Stomach. Oxford University Press, New York. 